\title{
NILAI PENDIDIKAN KARAKTER DALAM RAGAM GERAK TARI MAYANG RONTEK KABUPATEN MOJOKERTO
}

\author{
Leni Nur Halita \\ Jurusan Pendidikan Guru Sekolah Dasar, \\ Fakultas Keguruan dan Ilmu Pendidikan, \\ Universitas Muhammadiyah Malang \\ Jl. Raya Tlogomas No.246 Malang 65144, Indonesia \\ Email: lenihalitalita@gmail.com \\ Belinda Dewi Regina \\ Jurusan Pendidikan Guru Sekolah Dasar, \\ Fakultas Keguruan dan Ilmu Pendidikan, \\ Universitas Muhammadiyah Malang \\ Jl. Raya Tlogomas No.246 Malang 65144, Indonesia
}

\begin{abstract}
ABSTRAK
Penelitian ini bertujuan untuk mengetahui nilai Pendidikan karakter yang terdapat pada ragam gerak Tari Mayang Rontek kabupaten Mojokerto. Penelitian ini merupakan penelitian kualitatif dengan pendekatan deskriptif. Objek penelitian ini ialah ragam gerak Tari Mayang Rontek. Sumber data primer, yaitu hasil pengamatan ragam gerak Tari Mayang Rontek melalui video Tari Mayang Rontek di youtube. Sumber data sekunder didapatkan dari artikel dalam jurnal, buku tentang Tari Mayang Rontek, dan dokumen lain yang memuat analisis penelitian yang dilakukan. Teknik pengumpulan data melalui studi pustaka. Studi pustaka dilakukan untuk memperoleh data yang sudah ada, baik berupa foto, video ataupun dokumen lain yang berhubungan dengan objek penelitian penelitian. Teknik analisis meliputi analisis data, sajian data, dan simpulan. Hasil penelitian ragam gerak Tari Mayang Rontek menunjukkan bahwa tarian ini mengandung nilai pendidikan karakter yang digambarkan dalam beberapa ragam gerakan. Ragam gerakan tersebut meliputi Melampah Songgo Nompo, bukak nggawar kanan dan kiri, mlampah ngloro, mentang nggawar, naga mangap, mlampah prapatan, kencrongan, bedhayan gajah oling, tumpang tali jombangan, dan lembeyan. Makna gerakan tersebut terdiri atas: 1) tentang rasa ikhlas dan bersyukur terhadap Tuhan Yang Maha Esa, 2) tentang masalah manusia beserta penyelesaiannnya, 3) tentang kehidupan manusia tidak akan selalu mulus, dan 4) tentang manusia memiliki sikap baik, buruk, dan memiliki hawa nafsu.
\end{abstract}

Kata kunci: Nilai, Pendidikan karakter, Tari Mayang Rontek.

\begin{abstract}
This study aims to determine the value of character education contained in the variety of Mayang Rontek Dance movements in Mojokerto district. This research is a qualitative research with a descriptive approach. The object of this study is the variety of Mayang Rontek Dance movements. The primary data source of this research is the results of observing the variety of Mayang Rontek Dance movements through video of Mayang Rontek on Youtube. The secondary data source is obtained from the collection of journals, books on Mayang Rontek Dance, and other documents containing analysis of research conducted. Data collection technique is through literary study. Literary study is conducted to obtain the existing data, either in the form of photos, videos or other documents related to the research object. Analysis techniques include analyzing data, presenting data, and concluding. The results of the various movements of the Mayang Rontek Dance show that this dance contains the value of character education which is depicted in various movements of the Mayang Rontek Dance. Some of the various movements include Melampah Songgo Nompo, bukak nggawar kanan dan kiri, mlampah ngloro, mentang nggawar, nogo mangap, mlampah prapatan, kencrongan, bedhayan gajah oling, tmpang tali jombangan, dan lembeyan. The meaning of movements is, 1) about sincerity and gratitude to God Almighty, 2) about human problems and their resolution, 3) about human life will not always be smooth, and 4) about humans having good, bad, and own attitudes lust.
\end{abstract}

Keywords: values, character education, Mayang Rontek Dance. 


\section{GEEAR Jumal Sai isulyaa}

\section{A. Pengantar}

Mojokerto merupakan salah satu daerah di Indonesia. Mojokerto terletak di pulau Jawa, lebih tepatnya Jawa Timur. Mojokerto merupakan salah satu kabupaten yang dikenal sebagai tempat bersejarah peninggalan kerajaan Majapahit. Peninggalanpeninggalan kerajaan Majapahit di kabupaten Mojokerto biasanya dimanfaatkan sebagai sarana pendidikan, kebudayaan, dan lain sebagainya.

Memajukan sistem pendidikan di Indonesia merupakan salah satu tujuan bangsa untuk mencetak generasi-generasi baru yang lebih baik. Menurut Nursyid Sumatmadja (2002:40) pendidikan merupakan proses perubahan perilaku yang berjalan secara tidak disengaja dan tidak direncanakan. Menurut $\mathrm{H}$. Fuad Ihsan (2005:1) pendidikan dimaknai sebagai usaha manusia untuk menggali potensi-potensi yang ada dalam diri, baik secara jasmani maupun rohani sesuai dengan nilai-nilai yang ada dalam masyarakat dan budaya. Dapat disimpulkan bahwa pendidikan ialah proses yang dialami oleh manusia untuk memperbaiki tingkah lakunya guna mengembangkan bakat yang ada pada dirinya dengan tujuan menjadi orang yang lebih baik lagi.

Menurut Solichin dkk (2011:129) bahwa, di seluruh dunia pendidikan kini sedang melakukan penelitian tentang perlunya membangkitkan pendidikan karakter. Ada beberapa faktor pertimbangan atas diterapkannya pendidikan karakter: (1) melemahnya hubungan dalam lingkungan keluarga. Seringkali dijumpai masalah di lingkungan keluarga, mengenai orang tua yang sibuk dalam bekerja ataupun masalah pribadinya, sehingga orang tua sering lupa akan perannya untuk memberikan arahan dan pendidikan karakter kepada anak, (2) keadaan lingkungan sekitar generasi milenial sekarang sangatlah memprihatinkan. Sering terjadi tawuran antar pelajar, mengkonsumsi obat-obatan terlarang, pembunuhan, pencurian, pelecehan seksual, dan lainlainnya. Hal-hal inilah yang menjadi alasan pentingnya pendidikan karakter untuk ditingkatkan dan diterapkan dalam kehidupan sehari-hari.

Pendidikan karakter dapat dilakukan dengan berbagai cara, contohnya, yaitu dengan memperkenalkan kesenian. Hubungan kesenian dengan masyarakat Mojokerto sangatlah dekat. Menurut Ki HajarDewantara (2011:189) kesenian adalah kebudayaan yang dapat muncul, berkembang, serta masih berhubungan dengan jiwa dan perasaan manusia. Peran seni, yaitu sebagai pengikat bangsa dan mempererat solidaritas suatu masyarakat. Berikut salah satu jenis kesenian yang ada di kabupaten Mojokerto yang dapat digunakan sebagai penerapan pendidikan karakter, yaitu seni tari. Seni tari yang terkenal dan menjadi ciri khas kabupaten Mojokerto yaitu, Tari Mayang Rontek.

Tari Mayang Rontek merupakan tarian yang terinspirasi dari adat atau tradisi pernikahan yang ada di kerajaan Majapahit. Tarian ini mennggambarkan proses arak-arakan pengantin putri untuk menyambut pengantin putra di kerajaan Majapahit. Pencipta karya tari ini bernama Pak Setu. Dengan perkembangan zaman, tarian ini pernah surut dan pernah tidak ditarikan lagi, kemudian pada tahun 2016 Tari Mayang Rontek mulai terdengar lagi sampai saat ini.

Saat ini di kabupaten Mojokerto, Tari Mayang Rontek diwajibkan sebagai materi pada ekstrakulikuler di sekolah-sekolah. Tari Mayang Rontek pernah dipentaskan di berbagai acara besar di kabupaten Mojokerto, meliputi tari massal di acara peringatan Hari Pendidikan Nasional dengan jumlah penari 50 orang pada 2 Mei 2014, festival Tari Mayang Rontek memperingati Hari Jadi Kabupaten Mojokerto, dan acara resmi Kenegaraan. Usaha untuk menampilkan tarian ini di segala kegiatan menunjukkan bahwa Tari Mayang Rontek merupakan tari yang spesial di kabupaten Mojokerto.

Tari Mayang Rontek bukan hanya sebagai sarana untuk olah raga dan olah rasa saja, akan tetapi tarian ini mampu dijadikan sebagai sarana untuk pendidikan. Di setiap ragam gerak Tari Mayang Rontek mengandung nilai-nilai yang bermanfaat untuk masyarakat Mojokerto. Ragam gerak Tari Mayang Rontek meliputi gerak maknawi, yaitu gerak yang mengandung makna, dan gerak murni, yaitu gerak yang menonjolkan nilai estetika. Seluruh ragam gerak Tari Mayang Rontek terinspirasi dari perjalanan hidup manusia. Perjalanan hidup manusia tidaklah selalu mulus, ada suka duka, baik buruk, dan selalu berhubungan baik antar sesama maupun dengan Tuhan.

Penelitian ini dilakukan untuk mengungkap nilai-nilai pendidikan karakter pada ragam gerak Tari Mayang Rontek karya Pak Setu. Analisis makna ragam gerak tarian ini tidak dilakukan pada keseluruhan ragam gerak Tari Mayang Rontek, tetapi hanya pada ragam gerak yang memiliki makna saja. Hasil penelitian ini dapat dijadikan referensi untuk mengkaji kembali nilai-nilai pendidikan karakter pada ragam gerak Tari Mayang Rontek di kabupaten Mojokerto agar dapat membawa kemajuan di bidang Pendidikan maupun budaya kabupaten Mojokerto. 
Jenis penelitian yang digunakan adalah penelitian kualitatif dengan menggunakan pendekatan deskriptif. Penelitian ini untuk menggambarkan fenomena dan menguraikan data yang ada sesuai dengan kondisi atau apa adanya. Objek penelitian ini adalah ragam gerak Tari Mayang Rontek. Sumber data penelitian ini didapatkan dari sumber data primer, yaitu hasil pengamatan ragam gerak Tari Mayang Rontek melalui video Tari Mayang Rontek yang ada di youtube, serta sumber data sekunder yang didapatkan dari pengumpulan artikel jurnal, buku tentang Tari Mayang Rontek, dan dokumen lain yang mengandung analisis penelitian yang dilakukan. Teknik pengumpulan data melalui studi pustaka. Studi pustaka dilakukan untuk memperoleh data yang sudah ada, baik berupa foto, video ataupun dokumen lainnya yang berhubungan dengan objek penelitian yang akan diteliti. Teknik analisis meliputi menganalisis data, menyajikan data, dan menyimpulkan.

\section{B. Pembahasan}

\section{Analisis makna ragam gerak Tari Mayang Rontek}

Analisis ragam gerak Tari Myang Rontek secara umum merupakan gambaran dari perjalanan kehidupan manusia, yaitu bahwa manusia hidup selalu ada baik, buruk, suka maupun duka. Tari Mayang Rontek menggambarkan adanya dua hal di dunia, meliputi adanya baik buruk dan adanya suka duka. Hal ini, dimaknai bahwa setiap menempuh kehidupan yang baru yaitu kehidupan dalam pernikahan akan menghadapi banyak hal dan rintangan yang baru.

Gerak dalam Tari Mayag Rontek dibagi menjadi 3 fase, yakni fase pembuka, fase inti, dan fase penutup. Setiap fase ini memiliki ragam gerak tersendiri beserta nama gerak masing-masing. Pada fase pembuka memiliki nama gerak yaitu mlampah sangga nampa, bukak nggawar kanan-kiri, singget, mlampah ngloro, menthang nggawar, naga mangap, mlampah prapatan, srisik/trisik, dan tanjak. Pada fase inti memiliki nama gerak yaitu mlampah lobo, bukak nggawar ndhuwur, singget puter, mlampah nguji kerep, kencrongan, dan srisik. Pada fase penutup memiliki nama gerak yaitu bedhayan gajah oling, menthang prapatan, ukel, sangga nampa ara, srisik, tanjak, mlampah lombo, singget, tumpang tali jombangan, tumpang tali surabayan dan tanjak.
Ada 10 ragam gerak maknawi yang ada pada Tari Mayang Rontek terdiri atas gerak melampah songgo nompo, bukak nggawar kanan dan kiri, mlampah ngloro, mentang nggawar, naga mangap, mlampah prapatan, kencrongan, bedhayan gajah oling, tmpang tali jombangan, dan lembeyan. Ke sepuluh ragam gerak tersebut dimaknai sebagai hubungan dengan Tuhan Yang Maha Esa dan perjalanan kehidupan manusia.

Di bawah ini, merupakan penjelasan dari analisis ragam gerak Tari Mayang Rontek.

Tabel 1. Analisis ragam gerak Tari Mayang Rontek

\begin{tabular}{|l|l|}
\hline \multicolumn{1}{|c|}{ Nama Gerakan } & \multicolumn{1}{c|}{ Makna } \\
\hline & $\begin{array}{l}\text { Manusia hidup hanya } \\
\text { menerima dari Yang } \\
\text { Maha Kuasa sesuai } \\
\text { dengan takaran } \\
\text { masing-masing. }\end{array}$ \\
\hline Melampah Sangga & \\
Nampa & \\
(Lengan kanan lurus ke \\
samping sejajar dengan \\
perut, jari-jari \\
menghadap ke atas. \\
Lengan kiri ditekuk ke \\
samping sejajar dengan \\
kepala membentuk siku \\
dengan telapak tangan \\
menghadap ke atas. \\
Posisi badan \\
menghadap depan, \\
pandangan lurus ke \\
depan. Kedua tumit \\
merapat dan kaki \\
Mendhak.)
\end{tabular}




\section{GE[AR Jumal soim Bualyan}

\begin{tabular}{|c|c|}
\hline $\begin{array}{l}\text { Bukak Nggawar Kanan } \\
\quad \text { dan Kiri } \\
\text { (Lengan kanan lurus ke } \\
\text { samping kanan bawah } \\
\text { sejajar dengan } \\
\text { pinggang, lengan kiri } \\
\text { ditekuk ke arah dalam } \\
\text { di depan pusar } \\
\text { mengarah ke kanan. } \\
\text { Kedua telapak tangan } \\
\text { menghadap ke dalam } \\
\text { (dilakukan sebaliknya). } \\
\text { Tolehan kepala } \\
\text { mengikuti pergerakan } \\
\text { lengan yang lurus ke } \\
\text { samping, jika lengan } \\
\text { kanan lurus ke samping } \\
\text { kanan maka tolehan ke } \\
\text { samping kanan dan jika } \\
\text { lengan kiri lurus ke } \\
\text { samping kiri maka } \\
\text { tolehan juga ke kiri } \\
\text { melihat ujung jari-jari } \\
\text { tangan. Posisi bahu } \\
\text { condong ke kiri dan } \\
\text { pinggul condong ke } \\
\text { kanan. Kedua kaki } \\
\text { mendhak dan kedua } \\
\text { lutut membuka } \\
\text { membentuk seperti } \\
\text { huruf O. Gerakan ini } \\
\text { dilakukan arah } \\
\text { sebaliknya) }\end{array}$ & $\begin{array}{l}\text { Membuka jalan hidup } \\
\text { atau mengawali } \\
\text { perjalanan hidup dan } \\
\text { membersihkan dari } \\
\text { semua rintangan. }\end{array}$ \\
\hline 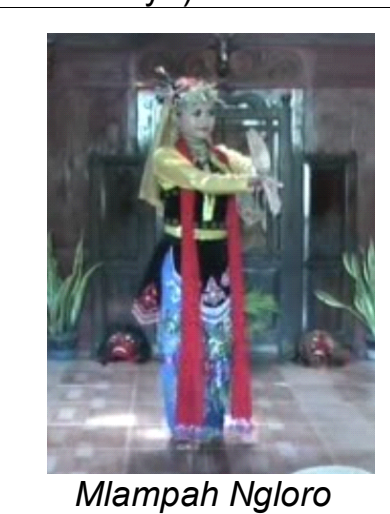 & $\begin{array}{l}\text { Perjalanan hidup } \\
\text { manusia sesuai } \\
\text { dengan kebutuhan, } \\
\text { dipercepat maupun } \\
\text { diperlambat (hidup itu } \\
\text { naik turun). }\end{array}$ \\
\hline
\end{tabular}

\begin{tabular}{|l|l|}
\hline (Lengan tangan kiri \\
ditekuk di depan pusar , \\
telapak tangan \\
menghadap ke bawah, \\
lengan tangan kanan \\
ditekuk di depan pusar \\
dengan posisi telapak \\
tangan menghadap \\
atas. Badan lebih \\
condong ke depan \\
mayuk, tolehan \\
kepala mengikuti \\
tangan kanan. Kedua \\
kaki mendhak, posisi \\
kaki bagian tungkai \\
kanan di depan napak \\
dan tungkai kiri di \\
belakang posisi ujung \\
kaki jinjit)
\end{tabular}




\begin{tabular}{|c|c|}
\hline $\begin{array}{l}\text { (Kedua pergelangan } \\
\text { tangan saling } \\
\text { menempel dengan } \\
\text { posisi pergelangan } \\
\text { tangan kiri berada di } \\
\text { atas dan pergelangan } \\
\text { tangan kanan di bawah } \\
\text { dan menghadap serong } \\
\text { ke kiri. Posisi dada } \\
\text { menghadap serong kiri, } \\
\text { tolehan kepala } \\
\text { mengikuti pergerakan } \\
\text { jari-jari yang berada di } \\
\text { atas. Kedua kaki } \\
\text { mendhak, tungkai kiri } \\
\text { berada di depan dan } \\
\text { tungkai kanan berada } \\
\text { di belakang dengan } \\
\text { posisi keduanya napak) }\end{array}$ & \\
\hline $\begin{array}{l}\text { Mlampah Prapatan } \\
\text { (Kedua lengan diayun } \\
\text { ke depan dan ke } \\
\text { belakang secara } \\
\text { bergantian. Tolehan } \\
\text { kepala kekanan dan ke } \\
\text { kiri mengikuti gerak } \\
\text { lengan yang diayun ke } \\
\text { depan, badan } \\
\text { menghadap ke depan } \\
\text { dan kedua kaki } \\
\text { mendhak. Kedua } \\
\text { tungkai mengikuti } \\
\text { pergerakan lengan, jika } \\
\text { lengan kanan di depan } \\
\text { tungkai kiri berada di } \\
\text { depan dan jika lengan } \\
\text { kiri di depam maka } \\
\text { tungkai kanan juga di } \\
\text { depan) }\end{array}$ & $\begin{array}{l}\text { Penjuru yang berasal } \\
\text { dari empat hawa } \\
\text { nafsu manusia. }\end{array}$ \\
\hline
\end{tabular}

\begin{tabular}{|c|c|}
\hline $\begin{array}{l}\text { Kencrongan } \\
\text { (Kedua lengan ditekuk } \\
\text { di atas bahu dengan } \\
\text { posisi ridong sampur } \\
\text { atau memegang } \\
\text { sampur. Posisi badan } \\
\text { mayuk ke depan dan } \\
\text { menghadap serong kiri, } \\
\text { tolehan kepala } \\
\text { menghadap serong kiri. } \\
\text { Tungkai kanan di } \\
\text { depan napak dan } \\
\text { tungkai kiri napak di } \\
\text { belakang tungkai } \\
\text { kanan) }\end{array}$ & $\begin{array}{l}\text { Permasalahan besar } \\
\text { dalam kehidupan } \\
\text { tergantung pada ulah } \\
\text { manusia itu sendiri. }\end{array}$ \\
\hline
\end{tabular}




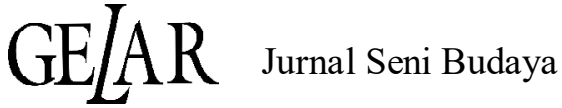

\begin{tabular}{|l|l|}
\hline & $\begin{array}{l}\text { Hidup manusia } \\
\text { sebuah simpul dan } \\
\text { hanya manusia itu } \\
\text { sendiri yang bisa } \\
\text { mengurai. }\end{array}$ \\
\hline $\begin{array}{l}\text { Tumpang Tali } \\
\text { Jombangan }\end{array}$ & \\
(Jari-jari tangan kiri \\
ngruji menghadap \\
depan dan lengan \\
kanan berada di atas \\
lengan kiri dengan jari- \\
jari menghadap ke \\
samping kiri. Tungkai \\
kanan gejug di \\
belakang dan tungkai \\
kiri napak di depan. \\
Badan serong kiri dan \\
kedua kaki mendhak)
\end{tabular}

\section{Nilai Pendidikan Tari Mayang Rontek}

Tari Mayang Rontek merupakan seni tari yang memiliki nilai-nilai pendidikan dan masih relevan dengan kehidupan saat ini. Nilai-nilai pendidikan yang ada pada ragam gerak Tari Mayang Rontek meliputi nilai religius, nilai tanggung jawab, nilai etika, dan nilai kepribadian.

Berdasarkan uraian 10 ragam gerak Tari Mayang Rontek tersebut, maka tarian ini tidak hanya sebagai media olah raga dan olah rasa saja tetapi dapat juga sebagai media pendidika. Makna pada setiap ragam gerak Tari Mayang Rontek merupakan contoh cara untuk memahami nilai pendidikan karakter. Dengan nilai pendidikan karakter ini dapat membantu manusia untuk memahami, menyadari, mengalami, serta mampu menempatkannya atau menerapkannya secara keseluruhan nilai-nilai yang ada dalam ragam gerak tarian tersebut dalam kehidupan sehari-hari.

Di bawah ini merupakan penjelasan nilai pendidikan karakter yang dapat dipahami dan dipelajari dari ragam gerak Tari Mayang Rontek:

a) Nilai Religius

Nilai religius ialah gambaran dari ragam gerak Melampah Sangga Nampa. Hal ini, terlihat saat penari melakukan gerakan tersebut. Melampah Sangga Nampa menceritakan sifat manusia yang selalu ikhlas dan bersyukur. Maksudnya adalah manusia hidup hanya menerima dari Yang Maha Kuasa sesuai dengan takaran masing-masing.

b) Nilai Tanggung Jawab

Nilai tanggung jawab ialah gambaran dari ragam gerak bedhayan gajah oling, dan tumpang tali jombangan. Pelajaran yang dapat dicontoh dari kedua ragam gerak tersebut adalah apapun permasalahan dalam kehidupan tergantung pada ulah manusia itu sendiri dan hanya manusia itu sendiri yang bisa menguraikan atau menghadapi masalah tersebut dengan rasa tanggung jawab.

c) Nilai Etika

Nilai etika ialah gambaran dari ragam gerak bukak ngawar kanan kiri, mlampah ngloro, mentang nggawar, kencrongan, dan lembeyan. Pelajaran yang dapat dicontoh dari kelima ragam gerak tersebut ialah kehidupan manusia adalah sebuah pilihan. Ada baik buruk dan naik turun, itu semua tergantung pada manusianya. Apakah mau mengawali hidup yang lebih baik lagi dan membersihkan segala rintangan kehidupan dengan berusaha menyeimbangka irama hidup di setiap perjalanannya. 
d) Nilai Kepribadian

Nilai kepribadian ialah gambaran dari ragam gerak naga mangap dan mlampah prapatan. Pelajaran yang dapat dicontoh dari kedua ragam gerak tersebut ialah manusia memiliki 2 sisi sikap, yaitu sisi baik dan sisi buruk. Selain itu, juga memiliki hawa nafsu. Untuk itu, jadilah pribadi yang positif agar berdampak positif untuk diri sendiri dan orang lain.

\section{Kesimpulan}

Berdasarkan pemaparan di atas, dapat disimpulkan bahwa Tari Mayang Rintek merupakan tarian khas kabupaten Mojokerto yang memiliki makna dan nilai pendidikan yang tercerminkan di dalam 10 ragam gerak maknawi. Beberapa ragam gerakannya, yaitu ragam gerakan Melampah Sangga Nampa, bukak nggawar kanan dan kiri, mlampah ngloro, mentang nggawar, naga mangap, mlampah prapatan, kencrongan, bedhayan gajah oling, tmpang tali jombangan, dan lembeyan. Makna gerakan tersebut terdiri atas: 1) tentang rasa ikhlas dan bersyukur terhadap Tuhan Yang Maha Esa, 2) tentang masalah manusia beserta penyelesaiannnya, 3) tentang kehidupan manusia tidak akan selalu mulus, dan 4) tentang manusia memiliki sikap baik, buruk, dan memiliki hawa nafsu.

Tari Mayang Rontek juga mengandung nilai pendidikan karakter, meliputi 1) nilai religious, 2) nilai tanggung jawab, 3) nilai etika, dan 4) nilai kepribadian. Oleh karena itu, Tari Mayang Rontek ini dapat dijadikan sebagai alat untuk membantu masyarakat kabupaten Mojokerto dalam membiasakan diri ketika akan melakukan sesuatu, berfikir, serta berprilaku sesuai dengan nilai-nilai budaya kabupaten Mojokerto. Makna yang terkandung dalam Tari Mayang Rontek ini dapat juga diterapkan dalam kehidupan sehari-hari oleh masyarakat kabupaten Mojokerto.

\section{KEPUSTAKAAN}

Atmodjo, Junus Satrio. 2009. Tari-tarian Majapahit Lenyap. Dalam Kompas, 11 November. Mojokerto.

Ayu DS. (2017). Bentuk Dan Fungsi Pertunjukan Tari Mayang Rontek Kabupaten Mojokerto Dalam Gelar Seni Budaya Daerah Jawa Timur Di Taman Budaya Surabaya. APRON, 2(10).

Bungin, Burhan. 2012. Analisis Data Penelitian Kualitatif. Jakarta: PT. Rajagrafindo Persada.

Gita PT. (2018). Nilai Pendidikan Karakter Dalam Ragam Gerak Tari Srimpi Pandelori. MUDRA, 33(2), 182-190.

Hadi, Y Sumandiyo. 2007. Kajian Tari Teks dan Konteks. Yogyakarta. Pustaka Book Publisher.

Puspitaning W. (2017). Gaya Gerak Tari Mayang Rontek Di Kabupaten Mojokerto. APRON, 2(10)

Wahyudiyanto. 2008. Pengetahuan Tari. Surakarta: CV Cendrawasih

Windi dwi SA, dan Sri Hadi. 2019. Makna Aimbolis Tari Mayang Rontek Di kabupaten Mojokerto. GREGET, 18(1). 